\title{
Correction to: Higher Education Landscape 2030
}

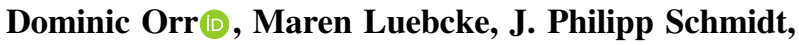 \\ Markus Ebner $\mathbb{D}_{\text {, }}$ Klaus Wannemacher $\mathbb{D}$, Martin Ebner $\mathbb{D}$, \\ and Dieter Dohmen
}

\section{Correction to: \\ D. Orr et al., Higher Education Landscape 2030, SpringerBriefs in Education, https://doi.org/10.1007/978-3-030-44897-4}

The original version of the book was inadvertently published with wrong corresponding author. The role of corresponding author for all chapters should have been Dieter Dohmen, not Dominic Orr, which has now been updated and approved by the authors. 